\title{
Consumer responses to hedonic food products: Healthy cake or indulgent cake? Could
}

dialecticism be the answer?

by

Alexander Jakubanecs *

Research Fellow

Centre for Applied Research at Norwegian School of Economics (NHH)

Helleveien 30

N-5042 Bergen

Norway

Ph.: +4755959752

E-mail: Alexander.Jakubanecs@snf.no

\author{
Alexander Fedorikhin \\ Associate Professor of Marketing \\ Kelley School of Business \\ Indiana University \\ 801 West Michigan Street, BS 4040 \\ Indianapolis, IN 46202-5151 \\ USA
}

Ph. (317) 278-8418

E-mail: sfedorik@indiana.edu

and

Nina M. Iversen
Professor
BI Norwegian Business School
Kong Christian Frederiks plass 5
5006 Bergen
Norway
Ph.: +47 46410194
E-mail: nina.m.iversen@bi.no

* Corresponding author

Acknowledgement: The authors are grateful to the Norwegian Research Council for funding.

Declarations of interest: none.

This is the author's manuscript of the article published in final edited form as:

Jakubanecs, A., Fedorikhin, A., \& Iversen, N. M. (2018). Consumer responses to hedonic food products: Healthy cake or indulgent cake? Could dialecticism be the answer? Journal of Business Research, 91, 221-232.

https://doi.org/10.1016/j.jbusres.2018.06.016 


\begin{abstract}
Marketing of indulgent food products with healthy claims (e.g., healthy cake) is challenging, and studies explaining consumer responses to such products are limited. This research addresses this limitation by focusing on an unexamined driver of responses to vice food products marketed as more healthy_dialectical thinking. Three experimental studies using samples from online panels show that dialecticism has a positive effect on consumers' evaluations of such products when primed within a predominantly non-dialectical culture, across cultures with different levels of dialecticism, and as an individual difference. In all three studies experienced discomfort mediates this effect. This research contributes to extant literature by (1) identifying the role of dialecticism in mitigating consumers' aversion to vice food products with healthy claims, (2) confirming the effects of dialecticism at both cultural and individual levels, and (3) highlighting the managerial relevance of dialecticism.
\end{abstract}

Keywords: Culture; Dialecticism; Vice products; Cross-cultural cognition; Goal conflict; International marketing 


\section{Consumer responses to hedonic food products: Healthy cake or indulgent cake? Could dialecticism be the answer?}

\section{Introduction}

The consumption of vice food products, or "guilty pleasures" (Giner-Sorolla, 2001), that offer immediate gratification but are harmful in the long run (Shiv \& Fedorikhin, 1999), is associated with the pursuit of hedonic goals (Belei, Geyskens, Goukens, Ramanathan, \& Lemmink, 2012). Fast food, a typical example of vice products, is closely associated with pleasure-seeking goals. At the same time, such food is synonymous with being harmful to health and long-term well-being (Nestle, 2003). Consumers' focus on hedonic characteristics of vice products undermines the self-control necessary to achieve and maintain a healthy lifestyle (Madzharov, Ramanathan, \& Block, 2016; Thomas, Desai, \& Seenivasan, 2011) and often results in lapses of self-control and choices that are suboptimal for reaching higherorder goals and long-term benefits (Shiv \& Fedorikhin, 2002).

Curbing the consumption of vice food products can be challenging because consumers may possess inherent preferences for this type of food (Nestle, 2003). As such preferences may be resistant to change, a promising strategy would be to make vice foods less unhealthy either by adding an ingredient that is beneficial for health or by removing a harmful one. In line with this strategy, marketers have tried to appeal to consumers by launching products such as Hershey's chocolate with extra antioxidants, Jif's creamy omega-3 peanut butter, and Pizza Hut's The Natural organic pizza with a honey-sweetened multigrain crust. However, marketing such products can prove challenging for most companies because of the conflict between the pursuit of hedonic goals activated by the vice product (Belei et al., 2012) and higher-order goals, such as living a healthy lifestyle (Fishbach \& Labroo, 2007), that are activated by the healthy claim. This conflict results in ambivalence following hedonic 
consumption that may lead to an aversive state on the part of consumers (Ramanathan \& Williams, 2007), which in turn may exert a negative impact on product quality perceptions, attitudes, price premiums, and purchases (van Doorn \& Verhoef, 2011). Such goal conflict may have contributed to the failure of Frito Lay's Flat Earth Chips and Burger King's "Satisfries" (Tuttle, 2014). Extant research examines the role of such factors as goal conflict (Belei et al., 2012), quality perceptions (van Doorn \& Verhoef, 2011), and consumer intutitions (Raghunathan, Naylor, \& Hoyer, 2006) in the consumption of indulgent products with healthy claims. However, research on the cultural factors underlying consumer responses to such products is lacking. To address this limitation, we focus on a factor previously unexamined in this context that may help consumers resolve, or at least mitigate, the goal conflict associated with vices that have healthy claims: dialectical thinking (Peng \& Nisbett, 1999; Wang, Batra, \& Chen, 2015).

From a theoretical perspective, understanding whether and how consumers differ in their ability to pursue both health-related and hedonic goals is important. From a managerial perspective, it is critical to identify factors that can reduce or at least mitigate the associated goal conflict and make less unhealthy hedonic products more palatable to consumers. With the current marketplace becoming increasingly globalized, understanding the impact of culture on the experience of goal conflict is imperative.

Existing cross-cultural research documents differences across Western and East Asian cultures in their ability to tolerate conflicting goals, cognitions, and affect (Peng \& Nisbett, 1999). Therefore, the detrimental effect of goal conflict is likely to be subject to cultural influences and to have significant consequences for corporate strategies. In addition to investigating the cross-cultural effect of dialecticism, we heed the call to examine cultural effects at the individual level (Briley, Wyer, \& Li, 2014; Kale \& Sudharshan, 1987). Thus, we assess consumers' differential responses to vices with healthy claims depending on the 
level of dialecticism - a concept that captures the ability to tolerate conflicting goals and contradictions (Peng \& Nisbett, 1999)— both across and within cultures. Study 1 shows the effects of the manipulated dialecticism on consumer attitudes and purchase intentions in the United States. Study 2 documents culture-level effects of goal conflict in food products (vices with healthy claims vs. vices with indulgent claims) on consumer attitudes and purchase intentions across the United States and China. Finally, Study 3 focuses on the effects of the dispositional trait of dialecticism on responses to food products with different levels of goal conflict.

Our main contribution to the extant research is demonstrating that dialectic thinking results in more favorable attitudes and purchase intentions toward indulgent food products with healthy claims by mitigating consumers' discomfort when they are exposed to such products. We ascertain these effects of dialecticism at both the cross-cultural and individual levels and highlight the managerial relevance of dialecticism.

\section{Theory and hypotheses development}

\subsection{Vices with healthy claims and goal conflict: Perspective from traditional goal and} attitude theories

Vices with healthy claims are likely to result in goal conflict for consumers exposed to these products (Fishbach \& Labroo, 2007). Goals, meanwhile, are internal representations of desired outcomes, events, or processes that cut across cognitive, personality, and motivational domains (Austin \& Vancouver, 1996; Carver \& Scheier, 1982). Goal theories assume that goals are organized within a hierarchical structure (Carver \& Scheier, 1982). Lower-order (short-term) goals, which are closely linked to action levels, constitute concrete means for reaching higher-order, more abstract, and more stable goals (Fishbach, Friedman, \& Kruglanski, 2003; Fishbach \& Labroo, 2007). 
Barsalou (1991) shows that goals influence products' cognitive representations in line with "goal-derived categories" that represent the extent to which a common goal defines an established food category. For example, people often consider fruits and vegetables inherently nutritious and thus categorize them as virtues that serve the higher-order, longterm goal of healthfulness. Conversely, people often classify indulgent foods (e.g., cake) as vices because they serve the lower-order, short-term goal of indulgence but are detrimental to the higher-order, long-term goal of staying healthy. Furthermore, matching vices with healthy claims to established goal-derived food categories (Barsalou, 1991; Ratneshwar, Pechmann, \& Shocker, 1996) such as virtues and vices (Chernev \& Gal, 2010; Wertenbroch, 1998) can be difficult because of contradictory or incongruent goals evoked by food products with combinations of healthy and indulgent attributes.

In general, the number of goals that an individual can pursue is relatively limited (Austin \& Vancouver, 1996), and studies show that the pursuit of multiple goals may lead to goal conflict when these are of a contradictory or incongruent nature (e.g., El Dahr \& Fort, 2008). Studies also document that the ability of a food product to satisfy either the indulgence or the healthfulness goal reduces the ability to satisfy the other goal (Belei et al., 2012; Raghunathan et al., 2006). Thus, traditional goal theorizing clearly indicates a goal conflict associated with the combination of vice products and healthy claims.

Goals are inherently intertwined with another core construct of social psychologyattitude, or the tendency to evaluate an entity with favor or disfavor (Eagly \& Chaiken, 1998). Attitudes are related to motivation insofar as they serve social identity goals. Specifically, attitudes help consumers connect with desired identities and dissociate themselves from undesirable identities (Eagly \& Chaiken, 1998). Furthermore, attitudes are characterized by internal consistency (Eagly \& Chaiken, 1998). States of conflict, by contrast, are usually associated with feelings of discomfort that individuals strive to resolve by re-establishing 
consistency (Kelly, Mansell, \& Wood, 2015). Thus, attitude inconsistency may be a source of discomfort in consumer responses to vices with healthy claims.

Because attitudes, according to traditional theory, are consistent, goals that are satisfied by respective attitudes are also likely to be consistent. Indeed, extant theories incorporating goals emphasize such a consistency in the structure of goals (Austin \& Vancouver, 1996). Thus, any goal conflict is a detrimental state that needs to be resolved. However, the theory of dialecticism introduces a different view of goal conflict to established theories.

\subsection{Attitudes, goals, and theory of dialecticism}

Considering that attitude and goal theories have been developed in the West (Austin \& Vancouver, 1996), a discussion of cultural factors is limited even in recent reviews (Bohner \& Dickel, 2011; Kelly et al., 2015). However, evidence shows that attitude and goal characteristics and functions may be different in non-Western cultural contexts (Riemer, Shavitt, Koo, \& Markus, 2014). Extant research finds that people perceive inconsistent facets of attitudes as less of a threat to their self-concept and experience inconsistency in attitudes more comfortably in non-Western than Western contexts (Heine \& Lehman, 1997). Members of non-Western cultures are also more comfortable in pursuing conflicting goals (Miller, Das, \& Chakravarthy, 2011; Spencer-Rodgers, Williams, \& Peng, 2010).

According to Peng and Nisbett (1999), dialecticism helps explain differences in tolerance for inconsistencies in attitudes and goals. Dialecticism reflects a cognitive tendency to accept contradiction (Spencer-Rodgers et al., 2010), and dialectical thinkers are more often members of East Asian than Western cultures (Spencer-Rodgers et al., 2010). Therefore, predictions from traditional attitude theories may not necessarily apply to dialectics who show inconsistent attitudes (Peng \& Nisbett, 1999). For example, dialectics show in-group derogation and a preference for out-groups (Ma-Kellams, Spencer-Rodgers, \& Peng, 2011). 
In the goals domain, dialectics show a greater ability than non-dialectics to maintain intrinsic motivation when extrinsic goals are activated (Li, Sheldon, \& Liu, 2015).

Some debate in the literature remains about the extent to which cultural syndromes (Oyserman, Sorensen, Reber, \& Chen, 2009) such as dialecticism or individualism are characteristic of society at large or primarily exist in the minds of individuals (Wan \& Chiu, 2009). One increasingly popular belief is that even if the world were not organized into nation-states, cultural effects would still exist (Chiu \& Hong, 2007). We concur with researchers who emphasize the need to examine cultural differences at both the individual and cross-cultural levels (Briley et al., 2014; Kale \& Sudharshan, 1987), and we expect the underlying mechanism driving the dialectical tolerance for contradiction to transcend the cross-cultural level and to account for similar differences within a culture (Li et al., 2015; Ma-Kellams et al., 2011). Therefore, we propose that our hypotheses apply to dialecticism's effects at both levels.

In our study of vices with healthy claims, goal conflict is likely to result from a combination of the nature of the products (indulgencies) and the health claims attached to them. Extant research identifies simultaneous activation of higher-order, long-term, healthrelated goals and inconsistent lower-order, short-term, hedonic goals as a source of conflict (Austin \& Vancouver, 1996). From the traditional perspective (Austin \& Vancouver, 1996), such contradictory information creates ambivalence that is considered an unnatural state for non-dialectics, who strive for consistency in their attitudes and goals (Peng \& Nisbett, 1999). Such ambivalence can lead to lower attitudes and purchase intentions. By contrast, dialectics tend to perceive contradiction as a natural state. Thus:

H1. Dialectics will have more positive attitudes and purchase intentions toward highconflict vice products (e.g., healthy cake) than non-dialectics. 
Furthermore, because dialectics are more accepting of opposites in an attitude object, they may exhibit more positive attitudes toward mixed than pure information in a product (Williams \& Aaker, 2002). Thus:

H2. Dialectics will have more positive attitudes and purchase intentions toward highconflict than low-conflict vice products.

Conversely, contradiction and goal conflict should be detrimental to non-dialectics' attitudes and purchase intentions (DeMofta, Chao, \& Kramer, 2016; Spencer-Rodgers et al., 2010). Thus:

H3. Non-dialectics will have more positive attitudes and purchase intentions toward lowconflict than high-conflict vice products.

Dialectics experience ambivalence toward social issues more comfortably than nondialectics (Hamamura, Heine, \& Paulhus, 2008), and they experience less discomfort and tension in response to messages with mixed information (Williams \& Aaker, 2002). Nondialectics experience greater ambivalence and more discomfort in response to mixed than negative or positive messages (Wang et al., 2015). Therefore, when exposed to the combination of a health claim and a vice product (e.g., healthy cake), non-dialectics will likely experience discomfort, which will result in weaker preferences for and reduced purchase intentions toward the products (vs. the low-conflict combination of a hedonic claim with a vice product, such as "yummy cake"). Conversely, dialectics will not experience discomfort when presented with a high-conflict combination of claims and products. Thus:

H4. Experienced discomfort will mediate the effect of dialecticism on attitudes and purchase intentions.

\section{Overview of empirical investigation}


In study 1, we tested the hypothesized effects of dialecticism in the United States, a predominantly non-dialectical culture. ${ }^{1}$. Then, in Study 2 we examined these effects across two cultures - the United States and China - exhibiting variation along major dimensions, such as independence/interdependence (He, Chen, \& Alden, 2012) and dialectical thinking. To replicate across cultures the effects observed within culture in Study 1, we examined goal conflict across cultures having low and high dialecticism scores. China is representative of the Eastern dialectical tradition and thus is characterized by a dialectical thinking style (Peng \& Nisbett, 1999).

\section{Study 1}

In Study 1, we examined whether priming dialectical style has a significant effect on consumer attitudes and purchase intentions toward vice products with healthy claims within U.S. culture.

\subsection{Pretest}

We conducted a pretest to (1) verify the hedonic nature of a product (cake) used in prior research (Shiv \& Fedorikhin 1999) and (2) to identify claims that would prime hedonic and functional goals. We randomly assigned U.S. participants $(N=78)$ to either a hedonic or a functional claim condition.

We used two items to verify goal salience, anchored by 0 and 100: very much reminding of pleasurable aspects of eating/very much reminding of the importance of being healthy and not at all reminding of pleasurable aspects of eating/not at all reminding of the importance of being healthy. We created an index by subtracting the hedonic goal from the functional goal. Thus, the higher the index, the more the participants were reminded of the

\footnotetext{
${ }^{1}$ The United States can be classified as a predominantly non-dialectical culture, as nonHispanic whites (a non-dialectical ethnic group; Spencer-Rodgers et al., 2010) currently make up $62 \%$ of the population (Cohn, 2015).
} 
importance of being healthy (rather than of the pleasurable aspects of eating). Given the hedonic nature of the product, higher numbers would indicate a higher level of conflict. The pretest identified the following four claims as making more salient hedonic and functional goals, respectively: yummy and decadent and healthy and immunity boost (the other claims tested included delicious, scrumptious, organic, and wholesome). Organic claims may activate health-related goals similarly to health claims (Chen, 2007). The four selected product-claim combinations resulted in the lowest and highest levels of experienced conflict of all the claims in the pretest: $\left(\mathrm{M}_{\text {yummy }}=-33\right.$ vs. $\mathrm{M}_{\text {healthy }}=8 ; \mathrm{F}(1,77)=21.40, p<.01$; $\mathrm{M}_{\text {decadent }}=-23$ vs. $\left.\mathrm{M}_{\text {immunity boost }}=7 ; \mathrm{F}(1,77)=15.53, p<.01\right)$.

\subsection{Method}

We used a $2 \times 2 \times 2$ mixed design (prime: dialectical vs. non-dialectical thinking style; goal conflict: high vs. low; claim version [within-subject]: yummy and decadent vs. healthy and immunity boost). An international data provider conducted the study with its online panel in two stages. The merged batches included 144 U.S. participants $\left(\mathrm{M}_{\text {age: }} 34\right.$ years, $50 \%$ female). All the participants were ethnic Caucasian-American and had English as both their first and spoken-at-home language. We informed the participants that they would be participating in two allegedly unrelated studies. The "first study" manipulated thinking style by asking them to read a text from a Science article and to provide their own example in support of the material (Li, Masuda, \& Russell, 2014; Ma-Kellams et al., 2011). In the "second study," participants saw a picture of a cake described with one of the pretested claims (see Appendix) and then proceeded to complete the dependent measures. They next responded to manipulation check items of primed dialecticism, questions on product category involvement, and classification questions on age, gender, ethnicity, first language, and language spoken at home. 


\subsection{Independent variables}

\subsubsection{Dialectical thinking manipulation}

We primed dialectical thinking by having participants read a text titled "Aristotle got it all wrong” (Ma-Kellams et al., 2011), which focused on the ideas that (1) everything is always in constant flux because reality itself is a process; (2) reality is not precise or cut-anddried but rather is full of contradiction; and (3) nothing is isolated and independent, but rather everything is connected. We primed non-dialectical thinking with the text titled "Aristotle was right: Truth is truth," which emphasized the notions that (1) there exists an "essence," a stable core identity, function, and meaning behind both people and things, and (2) contradiction is only a temporary state meant to be ultimately resolved (see Appendix).

\subsubsection{Goal conflict manipulation}

We manipulated goal conflict by presenting a hedonic product (cake) with the following product claims: yummy/decadent (verified as hedonic and, thus, low conflict) and healthy/immunity boost (verified as functional and, thus, high conflict).

\subsection{Dependent measures}

We assessed attitudes using a four-item, 7-point scale $(\alpha=.98)$ anchored by positive/negative, very favorable/not at all favorable, good/bad, and likable/unlikable (MacKenzie, Lutz, \& Belch, 1986; Shiv \& Fedorikhin, 1999). We assessed purchase intentions with a three-item, 7-point scale $(\alpha=.99)$ anchored by likely/unlikely, probable/improbable, and possible/impossible (MacKenzie et al., 1986). We measured discomfort level with three items $(\alpha=.92)$ anchored by very comfortable/very uncomfortable, not conflicted at all/very conflicted, and not confused at all/very confused (Williams \& Aaker, 2002). We measured experienced conflict with the same two items as in the pretest. 
For our manipulation check of primed dialecticism, participants rated the extent to which their "thoughts focused on reality being full of contradiction"; "thoughts were about the idea that if there are two opposing views on an issue, they both can be right"; "thoughts focused on the idea that there always is one right answer to any problem"; and "thoughts were about reality being stable and logical." We used these four items to compute a dialectical thinking index and verified goal conflict manipulation with the goal activation index, like in the pretest.

\subsection{Results}

\subsubsection{Manipulation checks}

We ran the analyses on the merged batches from the two stages of data collection. As expected, one-way ANOVA on the dialectical thinking index showed the main effect of primed dialecticism: participants in the dialectical condition had significantly more contradictory (less logical) thoughts than those in the non-dialectical condition $\left(\mathrm{M}_{\text {dialectical }}=\right.$ 1.33 vs. $\left.\mathrm{M}_{\text {non-dialectical }}=-0.13 ; \mathrm{F}(1,142)=17.55, p<.001\right)$. One-way between-subjects ANOVA with the claim version and batch as the within-subject factors showed a higher activation of instrumental, healthy goals in the high-conflict condition (healthy/immunity boost cake), which indicated significantly higher levels of conflict than those in the lowconflict condition (yummy/decadent cake) $\left(\mathrm{M}_{\text {high conflict }}=-.39\right.$ vs. $\mathrm{M}_{\text {low conflict }}=-2.03 ; \mathrm{F}(1$, $140)=22.86, p<.001$ ). There were no other significant effects (of claim version $[p=.64]$, data collection batch $[p=.32]$, or the covariate of age $[p=.41])$.

\subsubsection{Product evaluations}

Mixed-design ANOVAs on product attitudes and purchase intentions yielded no significant main or interaction effects for the within-subject factor (claim version), so we combined the claim versions together for all our analyses. Levene's test confirmed 
homogeneity of variance between the two batches. ANOVAs on attitudes and purchase intentions with batch, dialecticism, and goal conflict and all the interactions between these factors showed no significant effects involving batch (Table 1). These analyses revealed significant main effects of conflict level, dialecticism, and the interaction of conflict level with primed dialecticism on attitudes toward cake $(\mathrm{F}(1,135)=25.22, p<.001 ; \mathrm{F}(1,135)=$ $5.33, p<.05 ; \mathrm{F}(1,135)=8.82, p<.01$, respectively). For purchase intentions, only the effects of conflict level and the interaction were significant $(\mathrm{F}(1,135)=23.08, p<.001 ; \mathrm{F}(1$, $135)=6.52, p<.05)$.

Table 1 about here

As hypothesized (H1), priming dialecticism had positive effects on attitudes and purchase intentions toward high-conflict products (attitudes: $\mathrm{M}_{\text {dialectics }}=5.16 \mathrm{vs} . \mathrm{M}_{\text {non-dialectics }}=$ $3.88, p<.001$; purchase intentions: $\mathrm{M}_{\text {dialectics }}=4.70$ vs. $\left.\mathrm{M}_{\text {non-dialectics }}=3.77, p<.05\right)$. Dialectics showed similar attitudes and purchase intentions toward high- and low-conflict products (attitudes: $\mathrm{M}_{\text {high conflict }}=5.16$ vs. $\mathrm{M}_{\text {low conflict }}=5.65, p>.1$; purchase intentions: $\mathrm{M}_{\text {high }}$ conflict $=4.70$ vs. $\mathrm{M}_{\text {low conflict }}=5.31, p>.1$, contrary to $\mathrm{H} 2$ ), while non-dialectics showed more favorable attitudes and purchase intentions toward low- than high-conflict products (attitudes: $\mathrm{M}_{\text {low conflict }}=5.81$ vs. $\mathrm{M}_{\text {high conflict }}=3.88, p<.001 ;$ purchase intentions: $\mathrm{M}_{\text {low conflict }}=5.80 \mathrm{vs}$. $\mathrm{M}_{\text {high conflict }}=3.77, p<.001$; supporting H3). Table 2 shows means and standard deviations for the experimental cells.

Table 2 about here

\subsubsection{Moderated mediation analysis}

Confirming H4, moderated mediation analysis using Hayes's (2015) process macro, Model 7, showed that conflict level moderated the indirect effect of primed dialecticism on attitudes and intentions through experienced discomfort. This indirect effect was significant 
at the high-conflict level for both attitudes $(\beta=1.04,95 \%$ confidence interval $[\mathrm{CI}]$ excluding zero: .47 to 1.64$)$ and purchase intentions ( $\beta=1.09,95 \% \mathrm{CI}$ excluding zero: .48 to 1.72$)$, while the effect was not significant at the low-conflict level for either attitudes $(\beta=-.09$, 95\% CI including zero: -.52 to .32 ) or purchase intentions $(\beta=-.09,95 \%$ CI including zero: -.53 to .33$)$.

\subsection{Discussion}

Study 1 showed that primed dialectical thinking has an effect on attitudes and purchase intentions both across high- and low-conflict-level products and within highconflict-level products, in support of H1, H3, and H4. Experienced discomfort mediates the effect at the high level of conflict. H2 was not supported. A possible explanation is that the flexibility of thinking leads dialectics to accept products with different levels of goal conflict. Priming dialectical thinking in a predominantly non-dialectical Western culture may activate a thinking style that is still different from the theoretical definition of dialecticism grounded in the East Asian intellectual tradition. Therefore, to provide additional evidence, in Study 2 we conducted our investigation at the cross-cultural level.

\section{Study 2}

The goal of Study 2 was to replicate across cultures the effects that were observed within culture in Study 1. Thus, we examined goal conflict across cultures having low and high dialecticism scores: the United States and China, respectively.

\subsection{Method}

Study 2 included 126 consumers in the United States ( $\mathrm{M}_{\mathrm{age}}$ : 39 years, $44 \%$ female) and 134 in China ( $\mathrm{M}_{\text {age: }} 39$ years, 50\% female) recruited by the same data provider and randomly assigned to either the high or low goal conflict condition, resulting in a $2 \times 2 \times 2$ mixed design (culture: U.S. vs. China; goal conflict: high vs. low; claim version [within- 
subject]: yummy and decadent vs. healthy and immunity boost). In mainland China, the questionnaires were translated from English to Mandarin Chinese and back-translated. The participants in the online studies were ethnic Caucasian-American and Chinese consumers who were native speakers of the official languages in each country. We focused on Caucasians in the United States as a non-dialectical ethnic sub-group (Peng \& Nisbett, 1999).

We used the same pretested four product (cake) claim combinations as in Study 1. The procedure was identical to that of Study 1, except that Study 2 did not include a manipulation of dialecticism. Participants saw the picture of a cake with product claims (see Appendix) and then proceeded to complete the measures.

We used the same measures as in Study 1 for attitudes $(\alpha=.96)$, purchase intentions $(\alpha=.97)$, discomfort level ( $\alpha=.93)$, level of conflict, category involvement, and demographic questions. We added the 7-item Dialectical Self Scale ( $\alpha=0.72$; Ma-Kellams et al., 2011).

\subsection{Results}

\subsubsection{Manipulation checks}

One-way between-subjects ANOVA with the claim version as the within-subject factor showed a higher activation of instrumental goals in the high-conflict condition than in the low-conflict condition $\left(\mathrm{M}_{\text {high conflict }}=-.14\right.$ vs. $\mathrm{M}_{\text {low conflict }}=-1.33 ; \mathrm{F}(1,257)=33.43, p<$ .001 ). There were no other significant effects (of claim version $[p=.90]$ or the covariate of age $[p=.65])$.

\subsubsection{Dialecticism}

In line with extant research (Ma-Kellams et al., 2011), one-way between-subjects ANOVA showed that Chinese participants scored marginally higher on dialecticism than 
U.S. participants $\left(\mathrm{M}_{\text {China }}=4.50\right.$ vs. $\left.\mathrm{M}_{\mathrm{U} . \mathrm{S} .}=4.30 ; \mathrm{F}(1,258)=2.93, p<.10\right)$. The difference was smaller than we expected though.

\subsubsection{Product evaluations}

Mixed-design ANOVAs on product attitudes and purchase intentions showed no significant main or interaction effects of claim versions manipulated within subject. Thus, like in Study 1, we combined claim versions in all our analyses. We obtained significant main effects of country and conflict level and significant interactions of conflict level with country on attitudes $(\mathrm{F}(1,255)=18.50, p<.001 ; \mathrm{F}(1,255)=35.12, p<.001 ; \mathrm{F}(1,255)=20.53, p<$ .001 , respectively) and purchase intentions $(\mathrm{F}(1,255)=31.46, p<.001 ; \mathrm{F}(1,255)=28.14, p$ $<.001 ; \mathrm{F}(1,255)=14.26, p<.001$, respectively) (Table 3). In support of H1, Chinese participants had more positive attitudes and purchase intentions toward high-conflict products than U.S. participants (attitudes: $\mathrm{M}_{\text {China }}=5.57$ vs. $\mathrm{M}_{\mathrm{U} . \mathrm{S}}=4.18, p<.001$; purchase intentions: $\mathrm{M}_{\text {China }}=5.64$ vs. $\left.\mathrm{M}_{\mathrm{U} . \mathrm{S} .}=4.02, p<.001\right)$. Contrary to $\mathrm{H} 2$, Chinese participants had equally positive attitudes and purchase intentions toward high- and low-conflict products (attitudes: $\mathrm{M}_{\text {high conflict }}=5.57$ vs. $\mathrm{M}_{\text {low conflict }}=5.79, p>.1$; purchase intentions: $\mathrm{M}_{\text {high conflict }}=5.64$ vs. $\left.\mathrm{M}_{\text {low conflict }}=5.90, p>.1\right)$. U.S. participants had more positive attitudes and purchase intentions toward low- than high-conflict products (attitudes: $\mathrm{M}_{\text {low conflict }}=5.83 \mathrm{vs}$. $\mathrm{M}_{\text {high conflict }}$ $=4.18, p<.001$; purchase intentions: $\mathrm{M}_{\text {low conflict }}=5.58$ vs. $\mathrm{M}_{\text {high conflict }}=4.02, p<.001$ ), as predicted by H3. Table 4 shows the means and standard deviations for the cells.

Tables 3 and 4 about here

\subsubsection{Moderated mediation analysis}

We ran a moderated mediation analysis to show that conflict level moderates the indirect effects of culture on attitudes and intentions through experienced discomfort (H4). The effect was significant at the high-conflict level for both attitudes $(\beta=.65,95 \% \mathrm{CI}$ 
excluding zero: .44 to .88$)$ and purchase intentions $(\beta=.67,95 \% \mathrm{CI}$ excluding zero: .45 to $.90)$, but it was not significant at the low-conflict level for either attitudes ( $\beta=-.03,95 \% \mathrm{CI}$ including zero: -.18 to .13 ) or purchase intentions ( $\beta=-.03,95 \% \mathrm{CI}$ including zero: -.19 to $.13)$.

\subsection{Discussion}

Study 2 confirmed that the hypothesized effects of dialecticism also occur across cultures that are typical representatives of dialectical and non-dialectical thinking. Thus, we found support for $\mathrm{H} 1, \mathrm{H} 3$, and $\mathrm{H} 4$ for the four product-claim combinations representing high and low goal conflict. Similar to primed thinking styles, the cross-cultural effects of dialecticism on both product attitudes and purchase intentions are significant across high- and low-conflict-level products and within high-conflict products. . Chinese participants' attitudes and purchase intentions toward low-conflict products were as favorable as to high-conflict ones, contrary to H2. Similar to Study 1, at the high level of goal conflict, experienced discomfort mediates the effect of dialecticism at the culture level on attitudes and purchase intentions.

\section{Study 3}

The goal of Study 3 was to demonstrate that the differential responses to products with high- and low-conflict levels can be attributed to dialectical versus linear thinking styles at the individual level regardless of culture. In addition, the study aimed to verify the robustness of the effects with a different hedonic product: pizza (Shiv \& Fedorikhin, 2002).

\subsection{Method}

Study 3 included 175 consumers in the United States ( $\mathrm{M}_{\text {age }}$ : 26 years, 55\% female, Caucasian) and 167 in mainland China ( $\mathrm{M}_{\mathrm{age}}: 26$ years, $46 \%$ female) recruited by the same data provider. We manipulated goal conflict (high vs. low) between subjects and claim 
version (yummy and decadent vs. healthy and immunity boost) within subject and measured dialecticism as as a trait. Prior research classifies pizza as a typical vice product (Shiv \& Fedorikhin, 2002). Study 3 employs the same procedure and measures as in Study 2: attitudes $(\alpha=.95)$, purchase intentions $(\alpha=.97)$, discomfort level $(\alpha=.90)$, level of conflict, the Dialectical Self Scale $(\alpha=.69)$, category involvement, and demographic questions. Participants saw a picture of a pizza with product claims (see Appendix) and completed the measures afterward.

\subsection{Results}

\subsubsection{Manipulation checks}

One-way between-subjects ANOVA with the claim version as the within-subject factor showed significant main effects of conflict level with participants pooled across the United States and China. Those in the high-conflict condition reported a higher level of conflict than those in the low-conflict condition $\left(\mathrm{M}_{\text {high conflict }}=.10\right.$ vs. $\mathrm{M}_{\text {low conflict }}=-.98 ; \mathrm{F}(1$, $339)=59.38, p<.001)$, with a non-significant effect of the covariate of age $(p=.11)$.

\subsubsection{Product evaluations}

Similar to the first two studies, there were no significant main or interaction effects of the claim version manipulated within subject, so we combined claim versions in all our analyses. Regressions of trait dialecticism (measured by the Dialectical Self Scale; MaKellams et al., 2011), conflict level, and the interaction of dialecticism with conflict level on attitudes and intentions toward pizza yielded significant standardized coefficients (attitudes: $\beta$ $=0.13, p<.05 ; \beta=-0.20, p<.01 ; \beta=0.13, p<.05$, respectively; purchase intentions: $\beta=$ $0.10, p<.1 ; \beta=-0.18, p<.01 ; \beta=0.14, p<.01 ;$ Table 5). Furthermore, for exposition purposes, we performed a median split of participants pooled across the two countries on measurement of individual-level dialecticism to obtain two groups of thinkers (dialectical and 
non-dialectical/linear) and compared the two groups on product attitudes and purchase intentions for high- and low-conflict products.

Mixed-design ANOVAs on product attitudes and purchase intentions toward pizza yielded significant effects of conflict level and interactions of conflict level with dialectical thinking on attitudes $(\mathrm{F}(1,337)=12.72, p<0.001 ; \mathrm{F}(1,337)=6.63, p<.05$, respectively) and purchase intentions $(\mathrm{F}(1,337)=10.48, p<.01 ; \mathrm{F}(1,337)=5.24, p<.05$; Table 5). Participants with higher dialectical thinking showed more favorable attitudes $\left(\mathrm{M}_{\text {dialectical }}=\right.$ 5.38 vs. $\left.\mathrm{M}_{\text {non-dialectical }}=4.84, p<.01\right)$ and purchase intentions $\left(\mathrm{M}_{\text {dialectical }}=5.29\right.$ vs. $\mathrm{M}_{\text {non- }}$ dialectical $=4.91, p<.05$; supporting $\mathrm{H} 1)$ toward high-conflict products than non-dialectics. Those high in dialectical thinking showed no difference in attitudes or purchase intentions toward high- or low-conflict products (attitudes: $\mathrm{M}_{\text {high conflict }}=5.38$ vs. $\mathrm{M}_{\text {low conflict }}=5.51, p>$ .1 ; purchase intentions: $\mathrm{M}_{\text {high conflict }}=5.29$ vs. $\mathrm{M}_{\text {low conflict }}=5.42, p>.1$; contrary to H2). In support of H3 non-dialectics showed more favorable attitudes and purchase intentions toward low- than high-conflict products (attitudes: $\mathrm{M}_{\text {low conflict }}=5.63$ vs. $\mathrm{M}_{\text {high conflict }}=4.84, p<.001$; purchase intentions: $\mathrm{M}_{\text {low conflict }}=5.67$ vs. $\left.\mathrm{M}_{\text {high conflict }}=4.91, p<.001\right)$. Table 6 shows the means and standard deviations for the cells.

Tables 5 and 6 about here

\subsubsection{Moderated mediation analysis}

In support of $\mathrm{H} 4$, a moderated mediation analysis yielded a significant indirect effect of dialecticism at the high-conflict level for attitudes toward pizza $(\beta=.20,95 \% \mathrm{CI}$ excluding zero: .02 to .38$)$ and purchase intentions $(\beta=.22,95 \% \mathrm{CI}$ excluding zero: .02 to .41$)$ but yielded a non-significant effect at the low-conflict level for attitudes $(\beta=.02,95 \% \mathrm{CI}$ including zero: -.13 to .17$)$ and purchase intentions $(\beta=.03,95 \% \mathrm{CI}$ including zero: -.14 to .18). 


\subsection{Discussion}

In Study 3, we replicated the findings for Studies 1 and 2 with dialectical thinking as a trait and verified the robustness of the effects by finding support for $\mathrm{H} 1, \mathrm{H} 3$, and $\mathrm{H} 4$ for product attitudes and purchase intentions toward a different category of hedonic products. Like in the previous studies, H2 was not supported. Again, experienced discomfort at the high (but not the low) level of goal conflict mediated the effect of dialecticism at the individual level on attitudes and purchase intentions.

\section{General discussion}

The results show that the concept of dialectical thinking affects product evaluations and purchase intentions in the domain of food products with an inherent contradiction. In Study 1, we show that when dialectical thinking style is activated, Americans have more positive evaluations of and purchase intentions toward vices with healthy claims than when they are in a linear thinking mode. When in the latter mode, they are more comfortable with traditional vice products than with less unhealthy vices. This finding highlights the causal role of dialecticism in consumer responses to these types of products. In Study 2, at the crosscultural level, the tendency of the Chinese to accept greater contradiction in their environment, compared with Americans' greater tendency to view their world as predictable and logical, leads to a corresponding greater preference for vices with healthy claims. The search for pure hedonism (Sharma, Sivakuraman, \& Marshall, 2010), which is often characteristic of Western cultures, manifests itself in Americans' lower evaluations of and purchase intentions toward vices with healthy claims than traditional unhealthy vices. Finally, in Study 3, we replicate the results of the first two studies for trait of dialecticism with a different category of hedonic products and with dialecticism as a dispositional trait.

\subsection{Theoretical contributions}


We contribute to extant research in several ways. First, we show that incorporating the framework of dialectical thinking into consumer research on "guilty pleasures," which thus far has not incorporated cultural factors, may help better predict and explain responses to products with conflicting information. Second, we confirm the ability of dialectics to handle contradiction more comfortably than non-dialectics in the domain of vice food products. Prior research suggests that advertising appeals containing duality can be especially persuasive for members of dialectical cultures and people high in dialecticism (Williams \& Aaker, 2002). This could be because products focusing exclusively on hedonic goals are often undesirable in dialectical cultures (Tsai, 2007), as dialectics tend to prioritize balance over positivity, moderation over intensity, and complexity over purity (Spencer-Rodgers et al., 2010). This research shows that this may not be the case in the domain of vice food products. In this domain, individuals high in dialecticism do not necessarily seek out contradiction in vice food products; rather, they may just comfortably process contradiction when it is inherent in some products. As they respond favorably to both high- and low-conflict products, dialectics appear not to be averse to pure hedonism in their food products. Thus, dialecticism seems to operate differently in the motivational than judgmental domain, in which dialectics have more positive attitudes toward mixed than positive messages (Wang et al., 2015). Further research is necessary to identify domains and possibly different factors that determine differences in outcomes. A source of higher levels of comfort for dialectics may rest on their ability to enjoy hedonic products when the functional, health-related information is salient.

Furthermore, we confirm dialecticism as a variable that explains responses to food products with different levels of contradiction within a culture. We show that dialectical thinking can be induced among members of a predominantly non-dialectical culture, such as European-Americans in the United States. We also demonstrate that individual-level 
dialectics, who experience extensive contradiction in their environments, are influenced by this in their responses to contradictory stimuli.

\subsection{Conclusions}

The effects of dialecticism as an individual difference, in addition to dialecticism's primed and cross-cultural effects, show that dialecticism is not only a cultural but also an individual-level factor (Briley et al., 2014). In our research, we have underscored the importance of incorporating dialecticism into traditional attitude and goal theories to better understand consumer responses to goal conflict. Our findings have significant implications for marketers and policy makers, particularly in a predominantly non-dialectical culture such as the United States. Exposing non-dialectical consumers to less unhealthy vice products may trigger discomfort that leads them to forgo such products in favor of traditional less healthy vices, thus diminishing their well-being. Extant research suggests some strategies that may reduce consumption of vice food products and promote that of virtue food products (Block et al., 2011; Hausman, 2012; Mothersbaugh, Herrmann, \& Warland, 1993; Townsend \& Liu, 2012). This research makes additional contributions to the development of such strategies. Dialectics may possess a superior ability to make normatively rational decisions in their consumption choices, even in the face of ubiquitous hedonic marketing communications. For example, they may process healthy labeling information on vice products comfortably (Grunert, Fernández-Celemín, Wills, Bonsmann, \& Nureeva, 2010). Therefore, it is important to identify market segments that are high in dialecticism, such as by segmenting consumers on their recent Internet search terms (e.g., "contradiction," "Confucianism"), their viewing channel habits (e.g., MSNBC, Fox News), or other proxies for dialecticism, such as age and ethnicity (Asian-Americans and older consumers score higher on dialecticism; Williams \& Aaker, 2002). Strategies created to trigger the dialectical processing of information may expose consumers to stimuli containing elements of East Asian cultures (e.g., Chinese 
proverbs, such as "sorrow is born from excessive joy"). Such strategies may be especially effective for bilingual consumers, such as Chinese-Americans (Oyserman et al., 2009). However, the effectiveness of such strategies to identify and promote dialecticism is still unclear and should be pretested before possible application. Furthermore, the packaged foods industry, which produces many traditional vice food products, has recently suffered declining sales. Making less unhealthy products instead and targeting dialectics or promoting dialectical thinking in marketing communication may be a potentially successful strategy.

An important ethical issue arises when producers use only seemingly healthy ingredients in traditional vice food products (e.g., less processed sugar with the same amount of calories as the regular type). Marketers should avoid any misleading claims and use the suggested marketing strategies only on vice products that are truly less unhealthy than their traditional counterparts (e.g., products with real health-promoting ingredients, such as vitamins or omega-3). In addition, any such product modifications should be verified and endorsed by the FDA or other governmental or non-governmental organizations.

The results also suggest that local and multi-national companies in China and other dialectical countries should be able to successfully launch or promote vice food products with healthy claims. This is in line with the traditional Chinese view that food should not only provide pleasure but also improve health ( $\mathrm{Li}, \mathrm{Yin}, \&$ Saito, 2004). This philosophy is reflected in a product such as Chinese Yam Cake, which is believed to strengthen the spleen and nourish the kidneys.

We also acknowledge several limitations of this research. First, we employed a relatively explicit procedure, adopted from extant research, for promoting dialectical versus linear thinking. Further research could test other, more implicit procedures to promote dialectical thinking to increase the acceptance of vice products with healthy claims. Research 
should also examine the effect of dialecticism on consumer perceptions of healthfulness of such products. Second, as we included only two cultures, additional research is necessary to verify the validity of our findings for other Western and East Asian cultures. With the share of non-Hispanic whites in the U.S. population decreasing (Cohn, 2015), future studies should focus on other ethnic groups in the country. Researchers should also be cautious about generalizing the results of our research to the United States as a whole. Future studies could also extend our findings to domains with varying levels of conflict between hedonic and functional goals (e.g., exercising at the beach) to gain a better understanding of the effects of individual-level dialecticism.

Investigations show that the effects of dialecticism are of a conscious, cognitive nature (Ma-Kellams et al., 2011). Thus, examining whether the effects of dialecticism on evaluations and choices of consumer products are reversed under conditions of a cognitive load would be useful. Considering the reported negative correlation between dialecticism and the need for cognition (Haugtvedt, Petty, \& Cacioppo, 1992; Ng \& Hynie, 2014), future studies might investigate further how dialectics process information when they are experiencing goal conflict. Researchers should also develop strategies to identify consumer segments that are high in dialecticism and to promote dialectical thinking among those segments that are not. Finally, another fruitful direction would be to examine the effects of dialecticism among bilinguals and recent immigrants. 


\section{References}

Austin, J. T., \& Vancouver, J. B. (1996). Goal constructs in psychology: Structure, process, and content. Psychological Bulletin, 120(3), 338-375.

Barsalou, L. W. (1991). Deriving categories to achieve goals, The psychology of learning and motivation. In G. H. Bower (Ed.), Advances in research and theory (pp. 1-64). New York: Academic Press.

Belei, N., Geyskens, K., Goukens, C., Ramanathan, S., \& Lemmink, J. (2012). The best of both worlds? Effects of attribute-induced goal conflict on consumption of healthful indulgences. Journal of Marketing Research, 49(6), 900-909.

Block, L. G., Grier, S. A., Childers, T. L., Davis, B., Ebert, J. E. J., Kumanyika, S., ... \& Bieshaar, M. (2011). From nutrients to nurturance: A conceptual introduction to food well-being. Journal of Public Policy \& Marketing, 30(1), 5-13.

Bohner, G., \& Dickel, N. (2011). Attitudes and attitude change. Annual Review of Psychology, 62, 391-417.

Briley, D., Wyer, R. S., Jr., \& Li, E. (2014). A dynamic view of cultural influence: A review. Journal of Consumer Psychology, 24(4), 557-571.

Carver, C. S., \& Scheier, M. F. (1982). Control theory: A useful conceptual framework for personality, social, clinical, and health psychology. Psychological Bulletin, 92(1), $111-135$.

Chen, M. F. (2007). Consumer attitudes and purchase intentions in relation to organic foods in Taiwan: Moderating effects of food-related personality traits. Food Quality and Preference, 18(7), 1008-1021.

Chernev, A., \& Gal, D. (2010). Categorization effects in value judgments: Averaging bias in evaluating combinations of vices and virtues. Journal of Marketing Research, 47(4), 738-747. 
Chiu, C., \& Hong, Y. (2007). Social psychology of culture. New York: Psychology Press.

Cohn, D. V. (2015). Future immigration will change the face of America by 2065. Pew Research Center. Retrieved from http://www.pewresearch.org/fact$\operatorname{tank} / 2015 / 10 / 05 /$ future-immigration-will-change-the-face-of-america-by-2065/.

DeMofta, Y., Chao, M. C.-h., \& Kramer, T. (2016). The effect of dialectical thinking on the integration of contradictory information. Journal of Consumer Psychology, 26(1), 4052.

Eagly, A. H., \& Chaiken, S. (1998). Attitude structure and function. In D. T. Gilbert, S. T. Fiske, \& G. Lindzey (Eds.), The handbook of social psychology (4th ed., Vol. 1, pp. 269-322). New York, NY: McGraw-Hill.

El Dahr, H., \& Fort, F. (2008). Effect of goal salience and goal conflict on typicality: The case of "health food." In A. Y. Lee \& D. Soman (Eds.), Advances in Consumer Research (Vol. 35, pp. 282-288). Duluth, MN: Association for Consumer Research.

Fishbach, A., Friedman, R. S., \& Kruglanski, A. W. (2003). Leading us not unto temptation: Momentary allurements elicit overriding goal activation. Journal of Personality and Social Psychology, 84(2), 296-309.

Fishbach, A., \& Labroo, A. A. (2007). Be better or be merry: How mood affects self-control. Journal of Personality and Social Psychology, 93(2), 158-173.

Giner-Sorolla, R. (2001). Guilty pleasures and grim necessities: Affective attitudes in dilemmas of self-control. Journal of Personality and Social Psychology, 80(2), 206221.

Grunert, K. G., Fernández-Celemín, L., Wills, J. M., Bonsmann, S. S. g., \& Nureeva, L. (2010). Use and understanding of nutrition information on food labels in six European countries. Journal of Public Health, 18(3), 261-77. 
Hamamura, T., Heine, S. J., \& Paulhus, D. L. (2008). Cultural differences in response styles: The role of dialectical thinking. Personality and Individual Differences, 44(4), 932942.

Haugtvedt, C. P., Petty, R. E., \& Cacioppo, J. T. (1992). Need for cognition and advertising: Understanding the role of personality variables in consumer behavior. Journal of Consumer Psychology, 1(3), 239-260.

Hausman, A. (2012). Hedonistic rationality: Healthy food consumption choice using muddling-through. Journal of Business Research, 65(6), 794-801.

Hayes, A. F. (2015). An index and test of linear moderated mediation. Multivariate Behavioral Research, 50(1), 1-22.

He, Y., Chen, Q., \& Alden, D. L. (2012). Social presence and service satisfaction: The moderating role of cultural value-orientation. Journal of Consumer Behaviour, 11(2), $170-176$.

Heine, S. J., \& Lehman, D. R. (1997). Culture, dissonance, and self-affirmation. Personality and Social Psychology Bulletin, 23(4), 389-400.

Kale, S. H., \& Sudharshan, D. (1987). A strategic approach to international segmentation. International Marketing Review, 4(2), 60-70.

Kelly, R. E., Mansell, W., \& Wood, A. M. (2015). Goal conflict and well-being: A review and hierarchical model of goal conflict, ambivalence, self-discrepancy and selfconcordance. Personality and Individual Differences, 85, 212-229.

Li, L. M. W., Masuda, T., \& Russell, M. J. (2014). The influence of cultural lay beliefs: Dialecticism and indecisiveness in European Canadians and Hong Kong Chinese. Personality and Individual Differences, 68, 6-12.

Li, L. T., Yin, L. J., \& Saito, M. (2004). Function of traditional foods and food culture in China. Jarq-Japan Agricultural Research Quarterly, 38(4), 213-220. 
Li, Y. R., Sheldon, K. M., \& Liu, R. D. (2015). Dialectical thinking moderates the effect of extrinsic motivation on intrinsic motivation. Learning and Individual Differences, 39, 89-95.

MacKenzie, S. B., Lutz, R. J., \& Belch, G. E. (1986). The role of attitude toward the ad as a mediator of advertising effectiveness: A test of competing explanations. Journal of Marketing Research, 23(2), 130-143.

Madzharov, A. V., Ramanathan, S., \& Block, L. G. (2016). The halo effect of product color lightness on hedonic food consumption. Journal of the Association of Consumer Research, 1(4), 579-91.

Ma-Kellams, C., Spencer-Rodgers, J., \& Peng, K. P. (2011). I am against us? Unpacking cultural differences in ingroup favoritism via dialecticism. Personality and Social Psychology Bulletin, 37(1), 15-27.

Miller, J. G., Das, R., \& Chakravarthy, S. (2011). Culture and the role of choice in agency. Journal of Personality and Social Psychology, 101(1), 46-61.

Mothersbaugh, D. L., Herrmann, R. O., \& Warland, R. H. (1993). Perceived time pressure and recommended dietary practices: The moderating effect of knowledge of nutrition. Journal of Consumer Affairs, 27(1), 106-26.

Nestle, M. (2003). Food politics: How the food industry influences nutrition and health. Berkeley: University of California Press.

Ng, A. H., \& Hynie, M. (2014). Cultural differences in indecisiveness: The role of naive dialecticism. Personality and Individual Differences, 70, 45-50.

Oyserman, D., Sorensen, N., Reber, R., \& Chen, S. X. (2009). Connecting and separating mind-sets: Culture as situated cognition. Journal of Personality and Social Psychology, 97(2), 217-235.

Peng, K. P., \& Nisbett, R. E. (1999). Culture, dialectics, and reasoning about contradiction. 
American Psychologist, 54(9), 741-754.

Raghunathan, R., Naylor, R. W., \& Hoyer, W. D. (2006). The unhealthy = tasty intuition and its effects on taste inferences, enjoyment, and choice of food products. Journal of Marketing, 70(4), 170-184.

Ramanathan, S., \& Williams, P. (2007). Immediate and delayed emotional consequences of indulgence: The moderating influence of personality type on mixed emotions. Journal of Consumer Research, 34(2), 212-223.

Ratneshwar, S., Pechmann, C., \& Shocker, A. D. (1996). Goal derived categories and the antecedents of across category consideration. Journal of Consumer Research, 23(3), 240-250.

Riemer, H., Shavitt, S., Koo, M., \& Markus, H. R. (2014). Preferences don't have to be personal: Expanding attitude theorizing with a cross-cultural perspective. Psychological Review, 121(4), 619-648.

Sharma, P., Sivakumaran, B., \& Marshall, R. (2010). Impulse buying and variety seeking: A trait-correlates perspective. Journal of Business Research, 63(3), 276-83.

Shiv, B., \& Fedorikhin, A. (1999). Heart and mind in conflict: The interplay of affect and cognition in consumer decision making. Journal of Consumer Research, 26(3), 278292.

Shiv, B., \& Fedorikhin, A. (2002). Spontaneous versus controlled influences of stimulusbased affect on choice behavior. Organizational Behavior and Human Decision Processes, 87(2), 342-370.

Spencer-Rodgers, J., Williams, M. J., \& Peng, K. P. (2010). Cultural differences in expectations of change and tolerance for contradiction: A decade of empirical research. Personality and Social Psychology Review, 14(3), 296-312. 
Thomas, M., Desai, K. K., \& Seenivasan, S. (2011). How credit card payments increase unhealthy food purchases: Visceral regulation of vices. Journal of Consumer Research, 38(1), 126-139.

Townsend, C., \& Liu, W. (2012). Is planning good for you? The differential impact of planning on self-regulation. Journal of Consumer Research, 39(4), 688-703.

Tsai, J. L. (2007). Ideal affect cultural causes and behavioral consequences. Perspectives on Psychological Science, 2(3), 242-259.

Tuttle, B. (2014, August 14). The demise of "satisfries" and the sad history of healthy fast food. Time Money. Retrieved from http://time.com/money/3111817/burger-kingsatisfries-healthy-fast-food/.

van Doorn, J., \& Verhoef, P. C. (2011). Willingness to pay for organic products: Differences between virtue and vice foods. International Journal of Research in Marketing, 28(3), 167-180.

Wan, C., \& Chiu, C. (2009). An intersubjective consensus approach to culture: The role of intersubjective norms versus cultural self in cultural processes. In R. S. Wyer, C. Chiu, \& Y. Hong (Eds.), Understanding culture: Theory, research and application (pp. 79-92). New York: Psychology Press.

Wang, H., Batra, R., \& Chen, Z. (2015). The moderating role of dialecticism in consumer responses to product information. Journal of Consumer Psychology, 26(3), 381-394.

Wertenbroch, K. (1998). Consumption self-control by rationing purchase quantities of virtue and vice. Marketing Science, 17(4), 317-337.

Williams, P., \& Aaker, J. L. (2002). Can mixed emotions peacefully coexist? Journal of Consumer Research, 28(4), 636-649. 
Table 1: ANOVA results for Study 1.

\begin{tabular}{|c|c|c|c|c|c|}
\hline & Source & MS & $\mathbf{F}(1,135)$ & $\mathbf{p}$ & Partial $\eta^{2}$ \\
\hline \multirow[t]{8}{*}{ Product attitude } & Goal conflict & 51.59 & 25.22 & $.000 * * *$ & .157 \\
\hline & Dialecticism & 10.91 & 5.33 & $.022 *$ & .038 \\
\hline & $\begin{array}{c}\text { Goal conflict } \times \\
\text { dialecticism }\end{array}$ & 18.04 & 8.82 & $.004 * *$ & .061 \\
\hline & Batch & 2.65 & 1.30 & .257 & .010 \\
\hline & $\begin{array}{c}\text { Batch } \times \text { goal } \\
\text { conflict }\end{array}$ & .71 & .35 & .557 & .003 \\
\hline & $\begin{array}{c}\text { Batch } \times \\
\text { dialecticism }\end{array}$ & .74 & .36 & .548 & .003 \\
\hline & $\begin{array}{l}\text { Batch } \times \text { goal } \\
\text { conflict } \times \\
\text { dialecticism }\end{array}$ & 2.13 & 1.04 & .309 & .008 \\
\hline & Covariate: age & 2.6 & 1.27 & .262 & .009 \\
\hline \multirow{8}{*}{$\begin{array}{l}\text { Purchase } \\
\text { intentions }\end{array}$} & Goal conflict & 61.56 & 23.08 & $.000 * * *$ & .146 \\
\hline & Dialecticism & 1.72 & .65 & .423 & .005 \\
\hline & $\begin{array}{c}\text { Goal conflict } \times \\
\text { dialecticism }\end{array}$ & 17.40 & 6.52 & $.012 *$ & .046 \\
\hline & Batch & 4.00 & 1.50 & .223 & .013 \\
\hline & $\begin{array}{c}\text { Batch } \times \text { goal } \\
\text { conflict }\end{array}$ & .64 & .24 & .625 & .002 \\
\hline & $\begin{array}{c}\text { Batch } \times \\
\text { dialecticism }\end{array}$ & 1.61 & .60 & .438 & .004 \\
\hline & $\begin{array}{c}\text { Batch } \times \text { goal } \\
\text { conflict } \times \\
\text { dialecticism }\end{array}$ & 3.30 & 1.24 & .268 & .009 \\
\hline & Covariate: age & 4.79 & 1.79 & .183 & .013 \\
\hline
\end{tabular}

$* p<.05, * * p<.01, * * * p<.001$.

Table 2: Product attitudes and purchase intentions toward cake (standard deviations) as a function of primed dialecticism and product goal conflict.

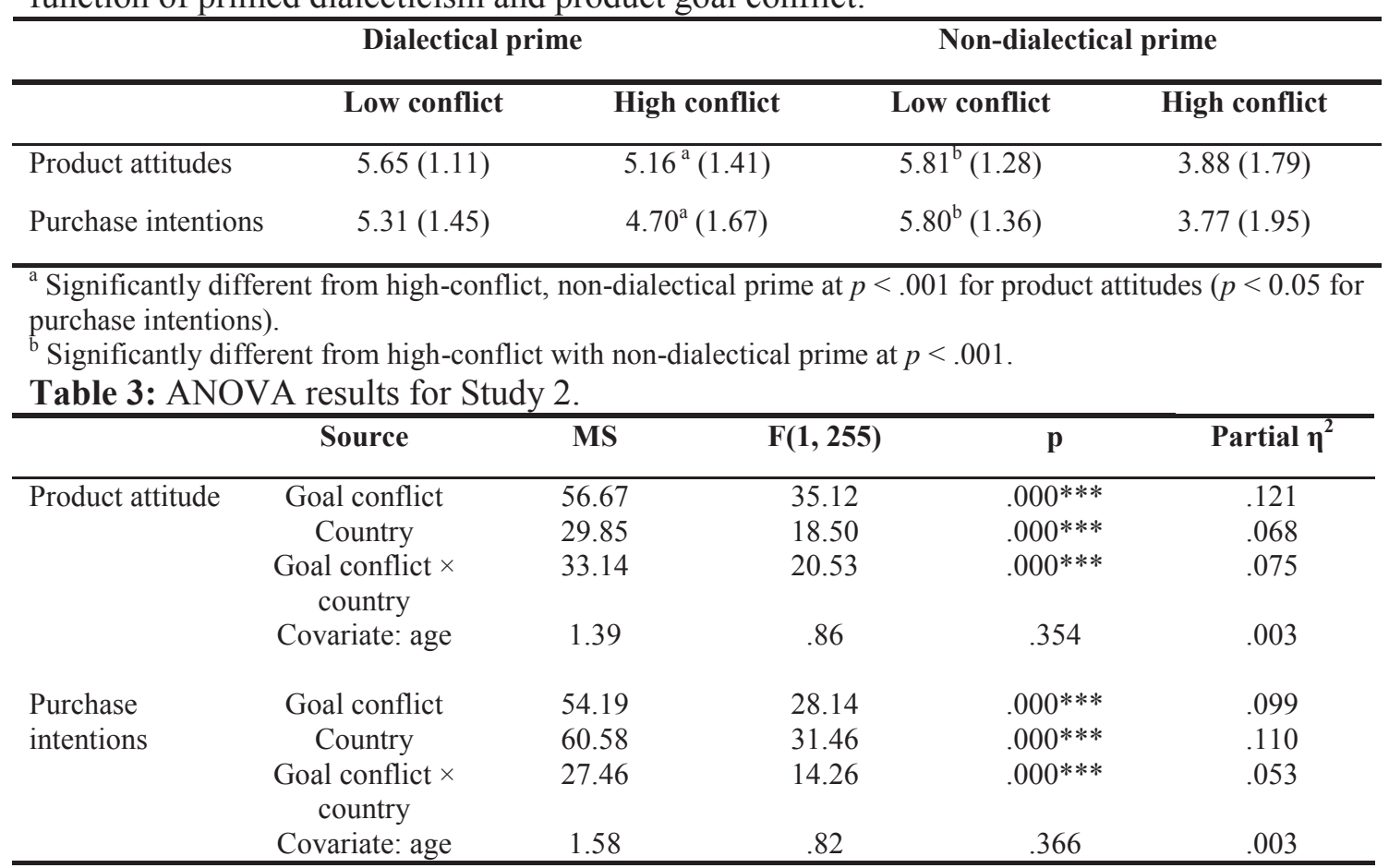

$* p<.05, * * p<.01, * * * p<.001$. 
Table 4: Product attitudes and purchase intentions toward cake (standard deviations) as a function of country (China vs. United States) and product goal conflict.

\begin{tabular}{lcccc}
\hline \multicolumn{2}{c}{ China } & \multicolumn{2}{c}{ U.S. } \\
\hline & Low conflict & High conflict & Low conflict & High conflict \\
\hline Product attitude & $5.79(1.01)$ & $5.57^{\mathrm{a}}(1.03)$ & $5.83^{\mathrm{b}}(1.10)$ & $4.18(1.78)$ \\
Purchase intentions & $5.90(1.07)$ & $5.64^{\mathrm{a}}(1.03)$ & $5.58^{\mathrm{b}}(1.39)$ & $4.02(1.91)$ \\
\hline
\end{tabular}

${ }^{a}$ Significantly different from high-conflict U.S. group at $p<.001$.

${ }^{\mathrm{b}}$ Significantly different from high-conflict U.S. group at $p<.001$.

Table 5: Regression and ANOVA results for Study 3.

\begin{tabular}{|c|c|c|c|c|c|}
\hline & Source & Adjusted $\mathbf{R}^{2}$ & Std. $\beta$ & $\mathbf{p}$ & VIF \\
\hline \multirow[t]{6}{*}{ Product attitude } & & .08 & & & \\
\hline & Goal conflict & & -.20 & $.000 * * *$ & 1.01 \\
\hline & Dialecticism & & .13 & $.012 *$ & 1.01 \\
\hline & $\begin{array}{c}\text { Goal conflict } \times \\
\text { dialecticism }\end{array}$ & & .13 & $.015^{*}$ & 1.01 \\
\hline & Covariate: age & & .14 & $.010 *$ & 1.01 \\
\hline & Source & MS & $\mathbf{F}(1,337)$ & $\mathbf{p}$ & Partial $\eta^{2}$ \\
\hline \multirow[t]{5}{*}{ Product attitude } & Goal conflict & 18.11 & 12.72 & $.000 * * *$ & .036 \\
\hline & Dialecticism & 3.63 & 2.54 & .111 & .008 \\
\hline & $\begin{array}{c}\text { Goal conflict } \times \\
\text { dialecticism }\end{array}$ & 9.44 & 6.63 & $.010 *$ & .019 \\
\hline & Covariate: age & 10.16 & 7.14 & $.008 * *$ & .021 \\
\hline & Source & Adjusted R $\mathbf{R}^{2}$ & Std. $\beta$ & $\bar{p}$ & VIF \\
\hline \multirow{6}{*}{$\begin{array}{l}\text { Purchase } \\
\text { intentions }\end{array}$} & & .08 & & & \\
\hline & Goal conflict & & -.18 & $.001 * *$ & 1.01 \\
\hline & Dialecticism & & .10 & .052 & 1.01 \\
\hline & $\begin{array}{c}\text { Goal conflict } \times \\
\text { dialecticism }\end{array}$ & & .14 & $.008 * *$ & 1.01 \\
\hline & Covariate: age & & .15 & $.004 * *$ & 1.01 \\
\hline & Source & MS & $\mathrm{F}(\mathbf{1}, \mathbf{3 3 7})$ & $\mathbf{p}$ & Partial $\eta^{2}$ \\
\hline \multirow{4}{*}{$\begin{array}{l}\text { Purchase } \\
\text { intentions }\end{array}$} & Goal conflict & 17.00 & 10.48 & $.001 * *$ & .030 \\
\hline & Dialecticism & .34 & .21 & .650 & .001 \\
\hline & $\begin{array}{c}\text { Goal conflict } \times \\
\text { dialecticism }\end{array}$ & 8.50 & 5.24 & $.023 *$ & .015 \\
\hline & Covariate: age & 13.81 & 8.51 & $.004 * *$ & .025 \\
\hline
\end{tabular}

$* p<.05, * * p<.01, * * * p<.001$.

Table 6: Product attitudes and purchase intentions toward pizza (standard deviations) as a function of individual-level thinking style (dialectical vs. non-dialectical) and product goal conflict.

\begin{tabular}{lcccc}
\hline \multicolumn{2}{c}{ Dialectics } & Non-dialectics \\
\hline & Low conflict & High conflict & Low conflict & High conflict \\
\hline Product attitude & $5.51(1.10)$ & $5.38^{\mathrm{a}}(1.31)$ & $5.63^{\mathrm{b}}(1.09)$ & $4.84(1.30)$ \\
Purchase intentions & $5.42(1.18)$ & $5.29^{\mathrm{a}}(1.44)$ & $5.67^{\mathrm{b}}(1.15)$ & $4.91(1.36)$ \\
\hline
\end{tabular}

${ }^{a}$ Significantly different from high-conflict, non-dialectics group at $p<.01$ for product attitudes $(p<.05$ for purchase intentions).

${ }^{\mathrm{b}}$ Significantly different from high-conflict, non-dialectics group at $p<.001$. 


\section{Appendix.}

Figure 1: Product attitudes toward cake as a function of primed dialecticism and product goal conflict.

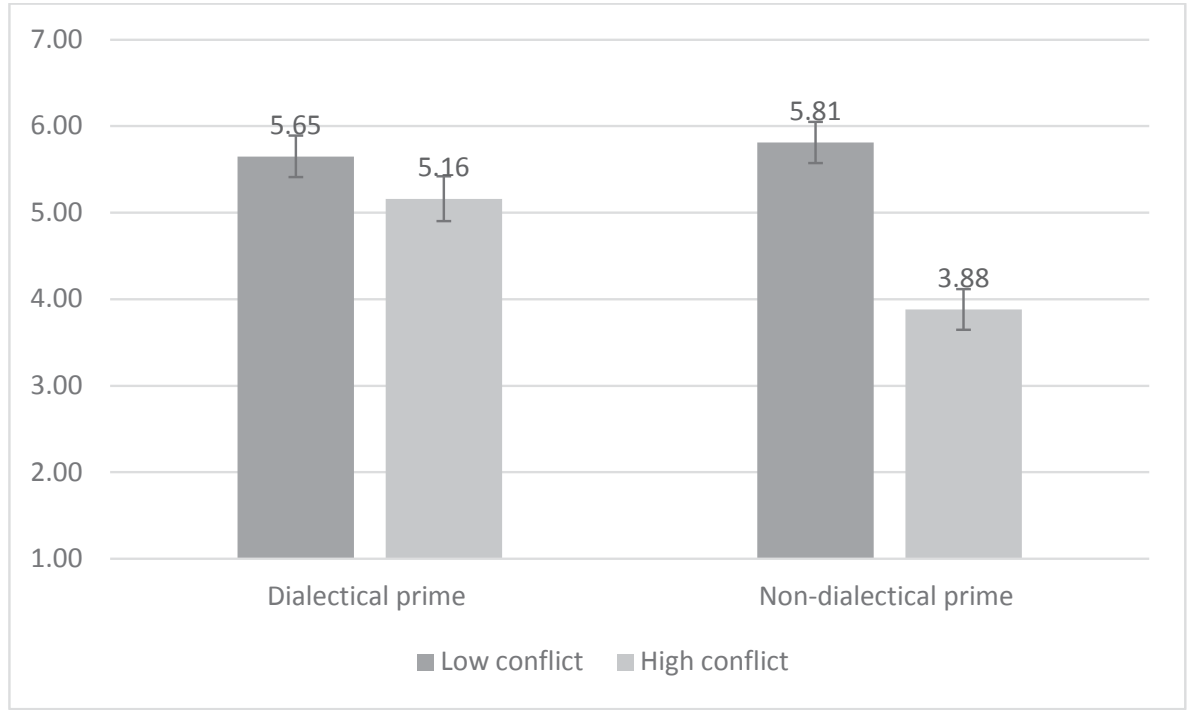

Figure 2: Purchase intentions toward cake as a function of primed dialecticism and product goal conflict.

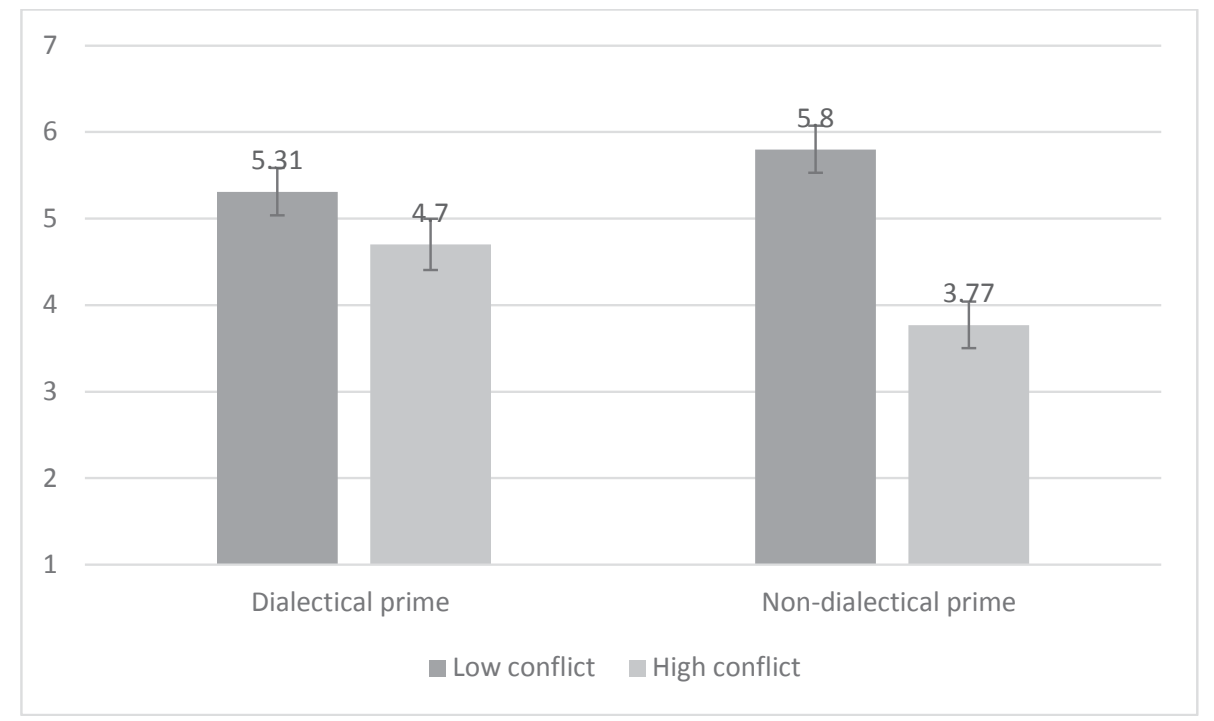


Figure 3: Product attitudes toward cake as a function of country (China vs. United States).

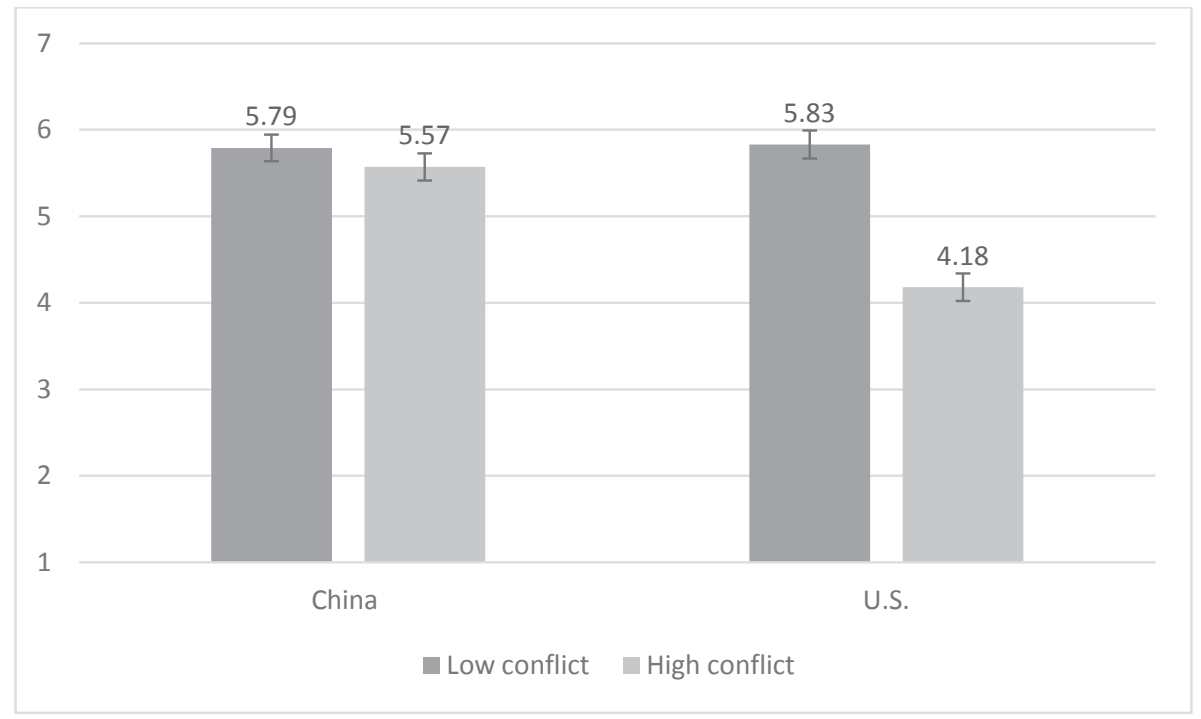

Figure 4: Purchase intentions toward cake as a function of country (China vs. United States).

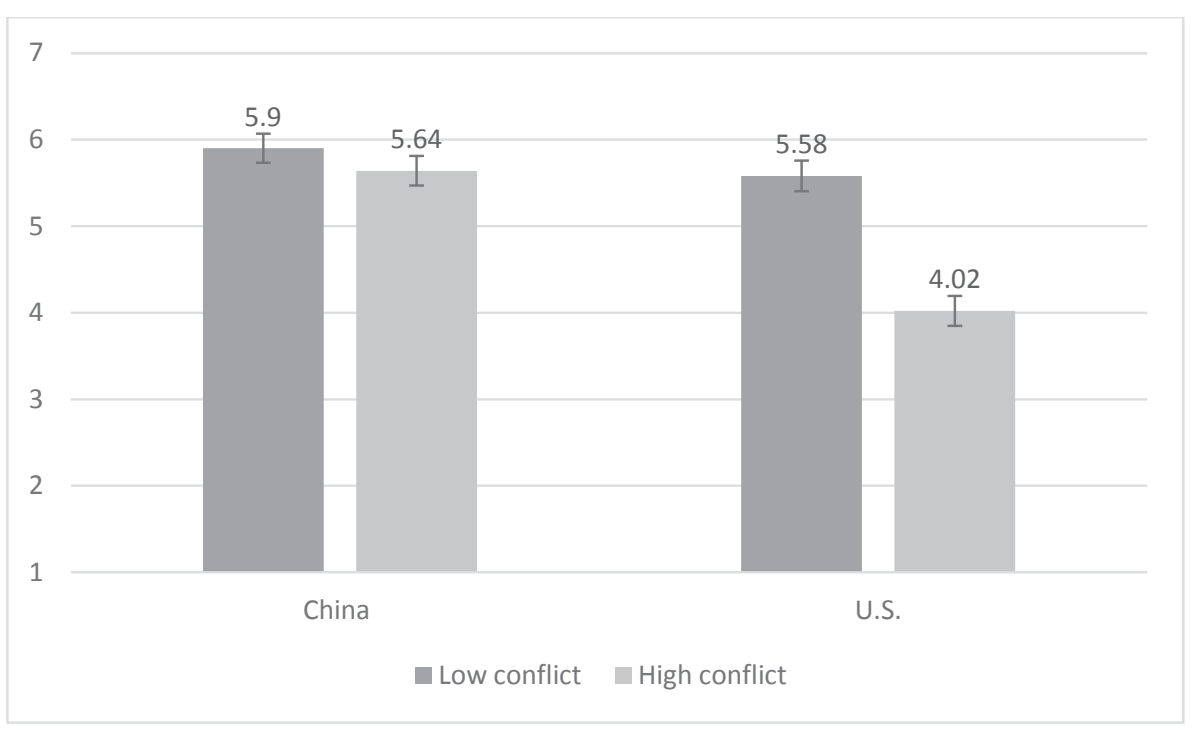


Figure 5: Product attitudes toward pizza as a function of individual-level thinking style.

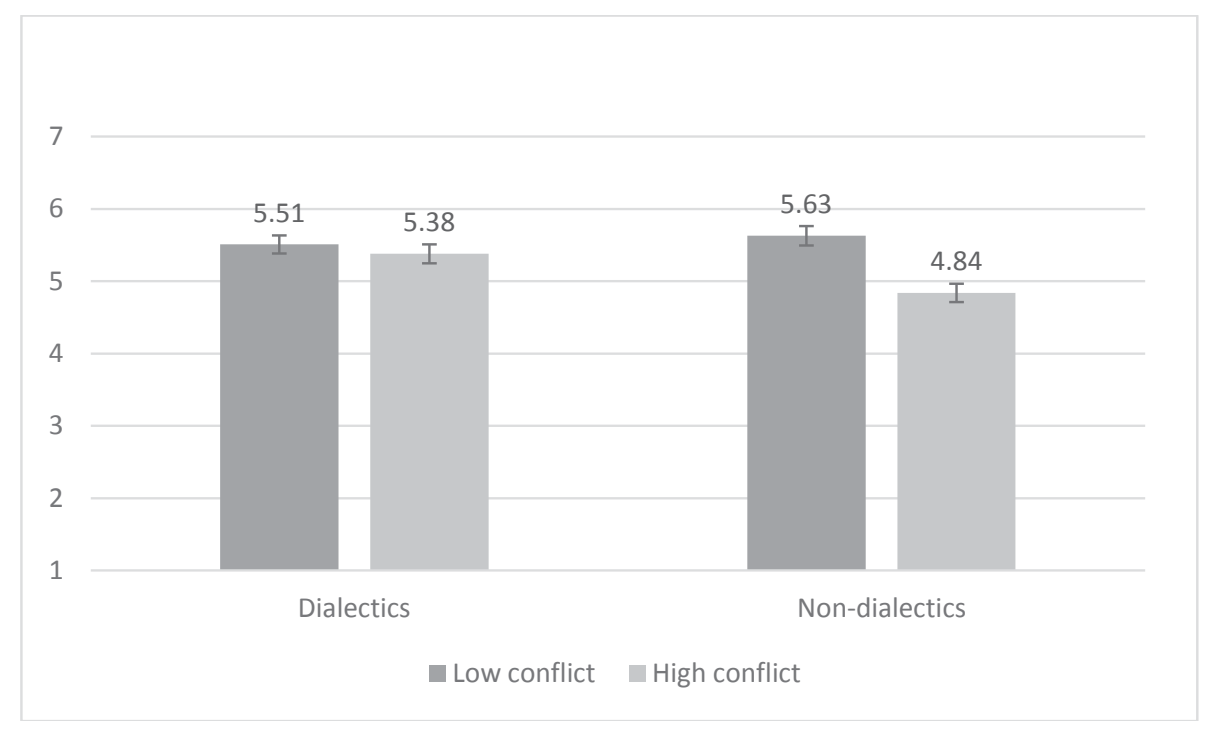

Figure 6: Purchase intentions toward pizza as a function of individual-level thinking style.

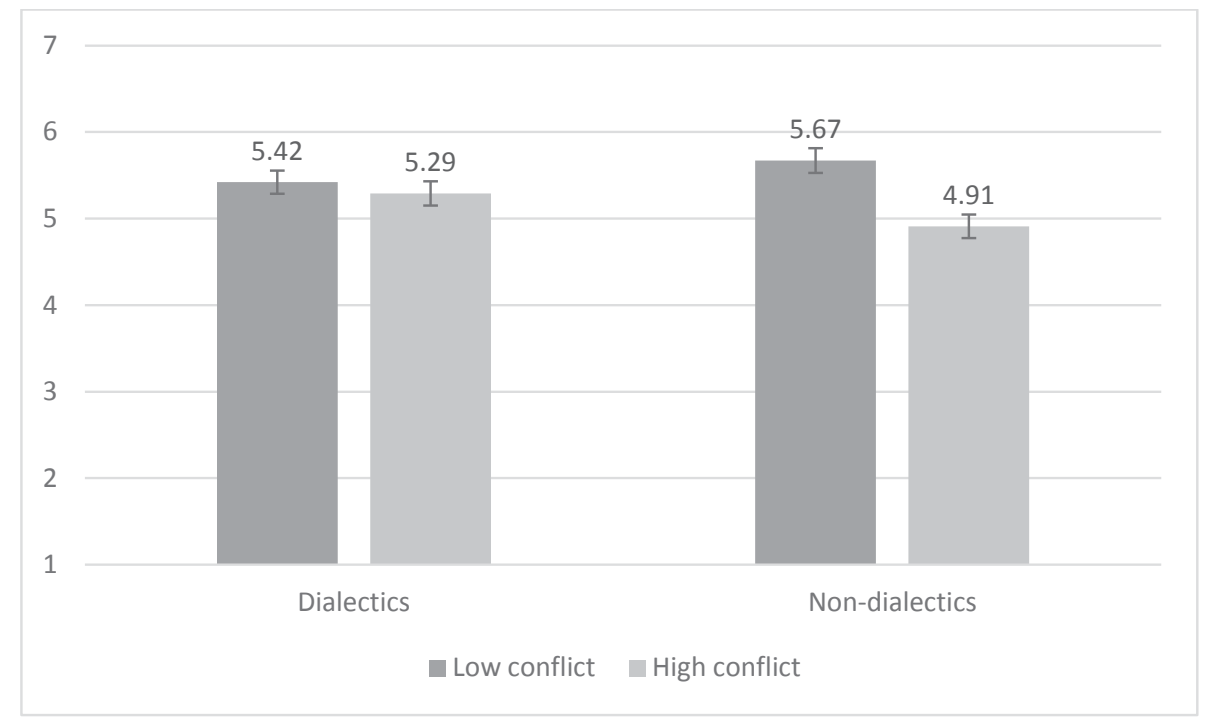




\section{Appendix}

\section{Dialectical condition}

Aristotle Got It All Wrong

Does truth depend on the situation? Based on conventional Western thought — which rests

substantially on the logic of Aristotle - this appears like a silly question. After all, ever since the ancient Greeks, we have been taught to believe that all logic is linear: "A equals A" (law of identity); "A cannot equal not-A" (law of noncontradiction). However, new research in the field of cultural psychology is proving that such "logical" Aristotelian reasoning may not be so rational after all: truth, it turns out, depends on the context.

A new series of cross-cultural studies have demonstrated that Eastern dialectical thinking emerges as a far more accurate view of reality. In simple terms, such dialecticism is grounded on the key principles that: 1) everything is always in constant flux, as reality itself is a process; 2) reality is not precise or cut-and-dried, but rather full of contradiction; and 3 ) nothing is isolated and independent, but rather everything is connected.

Currently, researchers across the world-from UC Berkeley in California to Peking University in the People's Republic of China-are examining the implications of such a shift in our conceptions of what is reasonable, logical, and functional. A group of professors and Ph.D. candidates from the University of Michigan, led by Richard Nisbett, have found, for example, that individuals who consider multiple sides of the same issue during problemsolving tasks tend to perform better, receive higher favorability ratings from their peers, and demonstrate greater overall psychological well-being.

"It's a very important finding," says Dr. Kaiping Peng, a professor in Berkeley's Institute for Personality and Social Research. "Philosophers have suspected this for centuries, but only now have we found empirical support for the idea that truth is context-dependent, and this principle has a crucial impact on the way we should function on a day-to-day level."

\section{Non-dialectical condition}

\section{Aristotle Was Right: Truth is Truth}

Is truth always truth? More than twenty centuries since the time of Aristotle-one of the most influential thinkers in Western intellectual history - this question still rises as a topic of hot debate. However, new research in the field of cultural psychology is proving that such linear thinking, based substantially on the rational foundations of Aristotelian reasoning, may be our best bet after all: truth, it turns out, is truth.

Based on Aristotle's logic, two key principles ground reality: 1) If anything is true, then it is true - thus, A equals A (law of identity). 2) No statement can be both true and false-A cannot equal not-A (law of noncontradiction). Now, a new series of cross-cultural studies have demonstrated that this kind of linear thinking is not only universal, but also functional. When pressed, individuals across the globe appear to subscribe to the notion that there exists an "essence," a stable core identity, function, and meaning, behind both people and things; contradiction, it follows, is only a temporary state meant to be ultimately resolved.

Currently, researchers across the world - from UC Berkeley in California to Peking University in the People's Republic of China - are examining the implications of such an understanding concerning what is reasonable, logical, and functional. A group of professors and Ph.D. candidates from the University of Michigan, led by Richard Nisbett, have found, for example, that individuals who seek to find the right answer during problem-solving tasks (as opposed to simply considering multiple sides of the same issue) tend to perform better, receive higher favorability ratings from their peers, and demonstrate greater overall psychological well-being. 
"It's a very important finding," says Dr. Junshi Qi, a visiting professor at Berkeley's Institute for Personality and Social Research. "Philosophers have suspected this for centuries, but only now have we found empirical support for the idea that truth is truth, and this principle has a crucial impact on the way we should function on a day-to-day level."

For both conditions the respondents received the instructions: "Now please give an example from your own life or from somebody you personally know well in support of the material in the article."

\section{Goal conflict manipulation (Studies 1 and 2)}

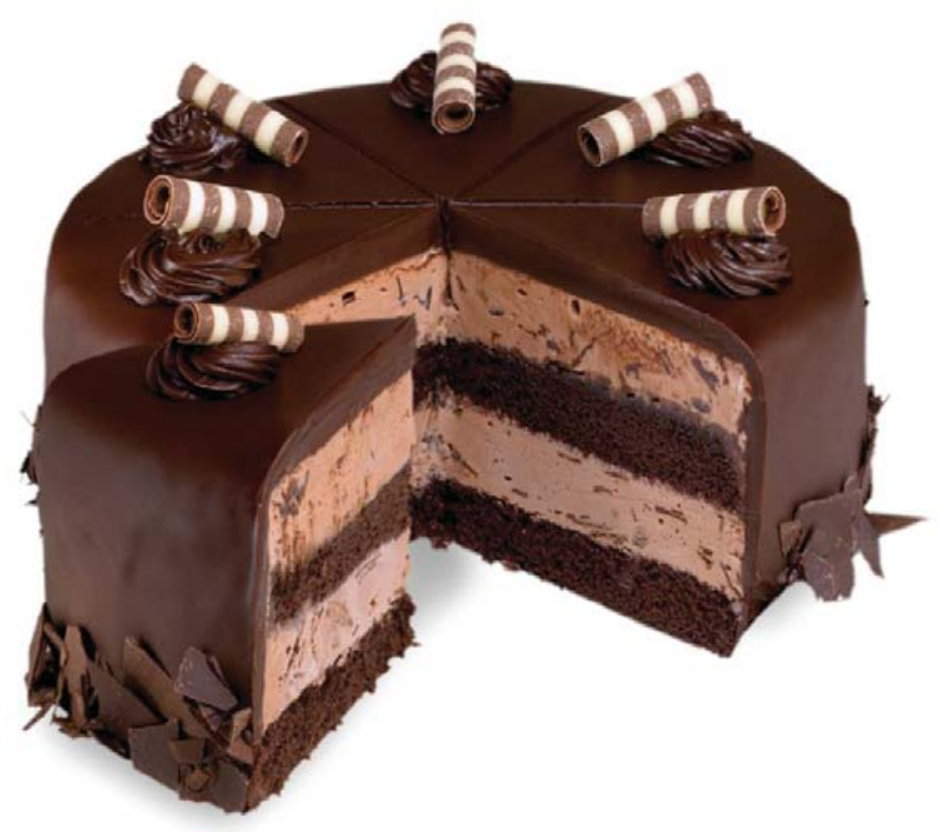

High conflict claims: healthy and immunity boost. Low conflict claims: yummy and decadent.

\section{Goal conflict manipulation (Study 3)}

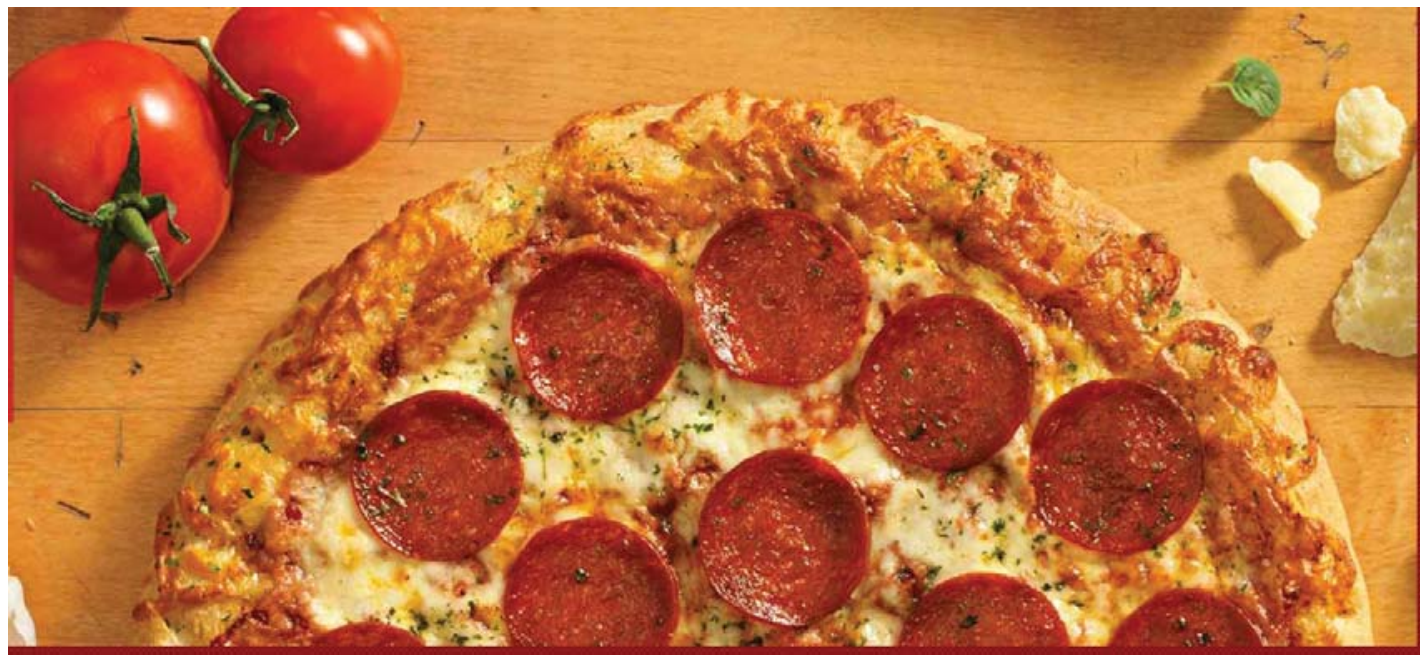

High conflict claims: healthy and immunity boost. Low conflict claims: yummy and decadent. 


\section{Highlights}

- Dialecticism explains consumer responses to vice food products with healthy claims.

- Dialecticism positively affects evaluations of less unhealthy vice food products.

- The effects hold for dialecticism both as a chronic and manipulated variable.

- Consumers' experienced discomfort mediates the effects of dialecticism. 


\section{Autobiographical note}

Alexander Jakubanecs is a Research Fellow at Centre for Applied Research at Norwegian School of Economics (NHH) in Bergen, Norway. He has published in such outlets as Journal of Brand Management, Journal of East-West Business, Advances in Consumer Research and International Journal of Market Research.

Alexander Fedorikhin is an Associate Professor of Marketing and has published widely in journals such as Journal of Consumer Research, Journal of Consumer Psychology, Journal of the Academy of Marketing Science, Organizational Behavior and Human Decision Processes.

Nina M. Iversen is a Professor of Marketing at BI Norwegian Business School. She has

published in Journal of Business Research, International Marketing Review, European Journal of Marketing and International Journal of Market Research. 